\title{
O mais simples poema a ver: Ave $e$ Solida
}

Vera Casa Noval UFMG/CNPq

Resumo: Este ensaio apresenta questões ligadas ao livro-objeto,ou livropoema, decorrentes do Poema Concreto e Poema Processo, que se colocam na contemporaneidade, tais como a abertura radical dos sentidos e as novas formas de ler.

Palavras-chave: Livro-objeto, Sentido háptico, Poema Concreto, Poema Processo, Ave, Solida.

Um Poema precisa de uma chave lógica para ser lido? O que o desenho de uma palavra, de um verso pode produzir? O poema precisa significar? comunicar?

O gráfico em seus movimentos peculiares como o dos acontecimentos dos anos de 1956 até hoje, se pensamos na computação gráfica, tem-nos oferecido esteticamente sensações extremas, experiências do visível do ato poético.

Discutir o sentido hoje parece ser a repetição das discussões das décadas de 1960/70. Didi-Huberman diz-nos que o homem tautológico "quererá não ver outra coisa além do que vê presentemente".

1. Didi-Huberman, G. O que vemos, o que nos olha. São Paulo: 34. 1998. p. 46 
O percurso das experimentações é intenso, expressivo, mas não tem mais o que Baudelaire dizia nos fins do século XIX sobre o poder de guardar "a forma e a essência divina".

O poema é forma geométrica que se dá a ver e até mesmo construir no manuseio das suas formas/imagens. Formas e volumes que indicam espaços a serem trabalhados constantemente nos enviam a desdobramentos os mais variados.O Poema Processo de Wlademir Dias Pino- Ave e Solida, por exemplo, ou os Poemóbiles de Julio Plaza ou Augusto de Campos em Poetamenos (1973) , para citarmos somente alguns livros-objetos, mostram a importância dessas formas.

O livro-poema, como era chamado pelos poetas do grupo Processo, ou a poesia-livro é "a incorporação do livro como elemento de expressão às palavras que compõem o poema”. ${ }^{2}$

Nessa conjunção inicial, o poema obedece a um ritmo e a uma semiografia próprias. A página/folha do livro elemento físico, tátil, participa intensamente na produção de sentidos. Trata-se como disse uma vez Ferreira Gullar "tornar audível o lado mudo da linguagem, o seu avesso", ou seja, uma possível escuta do visível é o que podemos inferir no processo - quando a "fisicalidade" do papel, parte integrante do poema e de seus sentidos faz existir o livro. É o livro físico o próprio gerador de sentidos através do processo de leitura.

A transparência através dos furos de estilete geradora da opacidade, onde sombras vão sendo projetadas na página pelas sucessivas perfurações se justapõem e se aglutinam no movimento de uma verdadeira dança do papel. Onde a palavra? O que parece interessar é esse movimento intenso que as mãos hapticamente vão traçando.

Vincos, dobras do papel, dobraduras, recortes, perfurações operam o espaço, cujo movimento se liga ao pensamento, apontando para o pensamento das artes nesse momento histórico.

A Ave voa; Sólida, solidão, só... apresentam um paradoxo que é doador de sentido. Se o paradoxo é o movimento que vai simultaneamente em duas direções divergentes, esses poemas-livro apresentam um pensamento "impossível" cujo paradoxo leva necessariamente à intensidade alta de sentidos.

2. CIRNE, M.; SÁ, Álvaro de. A origem do livro-poema. Rio de Janeiro: Vozes, 1971. p.49.

3. GULLAR, F. Rio de Janeiro: Suplemento dominical do JB, 22 mar. 1959. 
Lê-los é iniciar o devir do próprio poema. Não podemos esquecer que esses objetos apresentam um destino de consumação.

Com relação à legibilidade que vem do háptico e do movimento dos traços, dos signos verbais, do movimento interagindo com brilho, cor, corte, elasticidade, textura, esses poemas se articulam no paradoxo de um objeto fragmentado, desmembrado que têm uma lógica interna cujos sentidos emanam daí: a construção do poema durante sua leitura. O poema se faz enquanto ato de leitura.

Essa legibilidade, por outro lado, é construída estrategicamente pelos traços que o olho acompanha até encontrar a palavra. O importante durante o ato da leitura é a adesão do leitor a esse movimento simples de ir e vir das páginas. A mão ajuda a construir a leitura.

O corpo do poema é articulado como um todo orgânico. Contudo cada página conserva seu limite tátil, porque funciona como pausa, silêncio. No plano da percepção, o objeto-livro ou livro-poema é um continente que envolve um conteúdo que está no espaço objetivo, mas nunca visto, pois estamos habituados ao mundo verbal estático, fisicamente. Aí se instaura o paradoxo da presença e da ausência: Poema de onde a palavra se pode ausentar.

Esse corpo paradoxal que o livro-objeto parece ser faz com que passando página a página, ou seja, separando, fragmentando o corpo-livro, haja uma recombinação, em Solida, sobretudo, em seu último momento, quando surge uma possibilidade de escultura, dentro dos parâmetros neoconcretos e a gêneses do sentido.

Pode-se assim pensar em um movimento como fenômeno formal estruturado. O que aparece é uma escultura em papel - como aquelas de Amílcar de Castro, Lygia Clark ou Helio Oiticica (Relevo espacial, 1959).

A leitura dos dois livros-poemas vai se efetivar entre o gráfico: traço - linhas, letras - palavras, folha - página - cor e mão.

A relação da mão e do olho nos lembra Deleuze é "infinitamente mais rica, e passa por tensões dinâmicas, por inversões lógicas, trocas e vicariâncias orgânicas [...]. Mais a mão está subordinada [ao olho], mais a vista desenvolve um espaço óptico 'ideal' e tende a apreender suas formas seguindo um código óptico."

4. DELEUZE. Francis Bacon: Logique de la sensation. Paris: Edt. de la différence, 1996. p.99. (tradução da autora) 
O háptico, assim, constrói a leitura pois toca com os olhos. Nesse espaço táctil-óptico desses livros ou poemas-objeto passamos de uma forma à outra, de uma forma livro a uma forma escultura.

Verdadeiros diagramas, cuja representação gráfica é realizada por meio de figuras geométricas (pontos, linhas, áreas) e das relações entre elas e as palavras, Ave e Solida estão no limite do livro enquanto códice, por isso deslocam a leitura e abrem possibilidades de manuseio e intervenção do leitor.

Essas intervenções são o que os poetas do Poema Processo chamaram de versões. O livro-poema permite versões, ou seja, ele é uma verdadeira oficina de criação na medida em que propõe reprodutividade:

Cada consumidor/participante/criativo ao explorar o processo cria ele próprio "versões", de acordo com seu repertório. Se o importante é a invenção de novos processos, todas as 'versões' têm igual valor, inclusive a do criador do processo, e os conceitos de bom e ruim são substituídos pela opção de cada um.

O conceito de expansão é aqui pensado, na medida em que as inúmeras possibilidades de criação, a partir de uma matriz, ou melhor, do poema-objeto original que se expande indo mesmo até as novas tecnologias, sob a forma de arte/games, por exemplo, quando a computação gráfica ajuda na formatação de outros destinos das imagens, outras configurações do visível e do legível.

Aparentemente a aridez geométrica dessa estética do livro-objeto não traz um apelo ao leitor, mas ao manipular as folhas/páginas o imaginário é despertadoe se inicia aí a co-autoria.

Livros-objetos, poemas-objetos que demandam um jogo espacial. As cores, a textura do papel, sugerem ao leitor de Ave signos a partir das perfurações. Você vê o que lê. Aí a simplicidade e sua complexidade ao mesmo tempo. Coreografias do poeta Wlademir Dias Pino.

Diante do poema-objeto Ave - o leitor parte do signo verbal para o visual segundo a indicação de seu autor.

5. SÁ, Álvaro de. Vanguarda: produto da comunicação. Rio de Janeiro: Vozes, 1975. p.55. 
- A ave voa para dentro de sua cor

- Polir o vôo

- Mais que um ovo

- Que tatear é seu contorno

- Sua aguda crista completa a solidão

- Assim é que ela é teto de seu olfato

E a curva amarga seu vôo e fecha um tempo com sua forma.

O signo verbal sob a perfuração circular, seguindo linhas que formam angulações e fazem o movimento do corpo e apontam para a dança dos signos faz acontecer um outro ritmo de leitura do poema.

Corpo físico que proporciona a dança através do jogo das forças que puxam o leitor para a direção proposta pelo autor, mas que não se ancora aí tão somente. Desliza conforme a inércia ou quebra o movimento muscular: "quero fazer uma arte móvel, mas principalmente, para o músculo do homem".

Resumé: Cet article présente quelques questions sur le livre-objet (ou livrepoème) advenues du Poème Concret et Poème Procès, qui sont pertinents dans la contemporaneité,telles que l'ouverture radicale des sens et les nouvelles façons de lire

Mots clés: Livre-objet, Le sens haptique, Poème concret, Poème procès, Ave et Solida.

6. Wlademir Dias Pino. In: SILVEIRA,P. A página violada. p.179. 


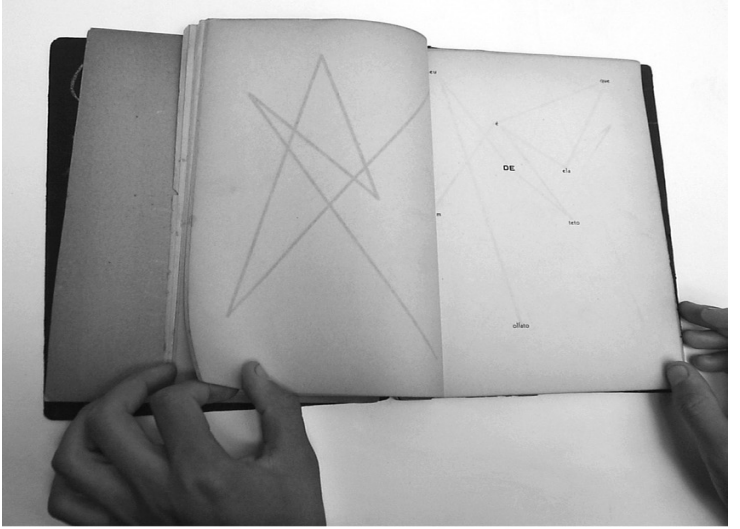

Ave (WDP)

acervo Neide de Sá

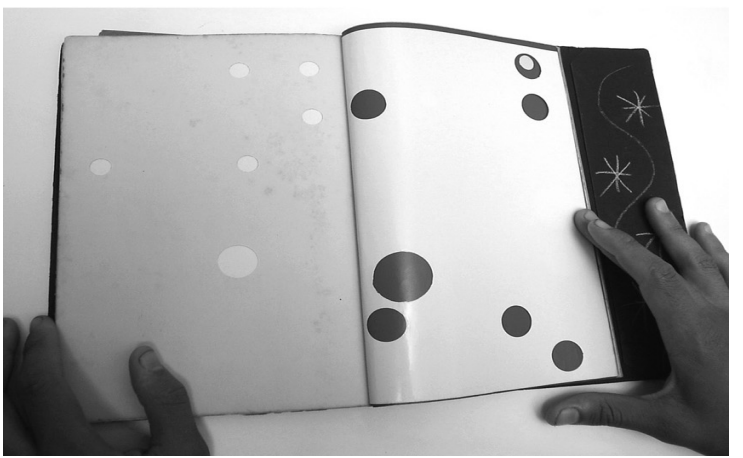

Ave (WDP)

acervo Neide de Sá

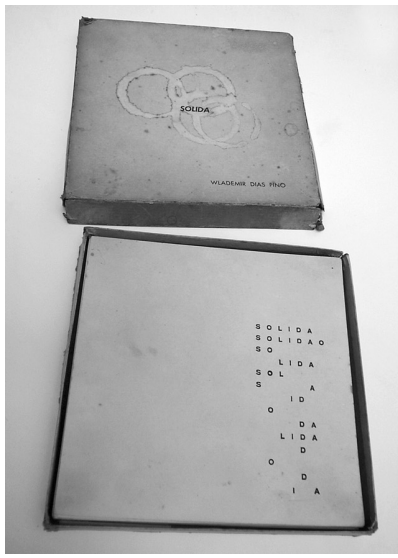

Solida (WDP)

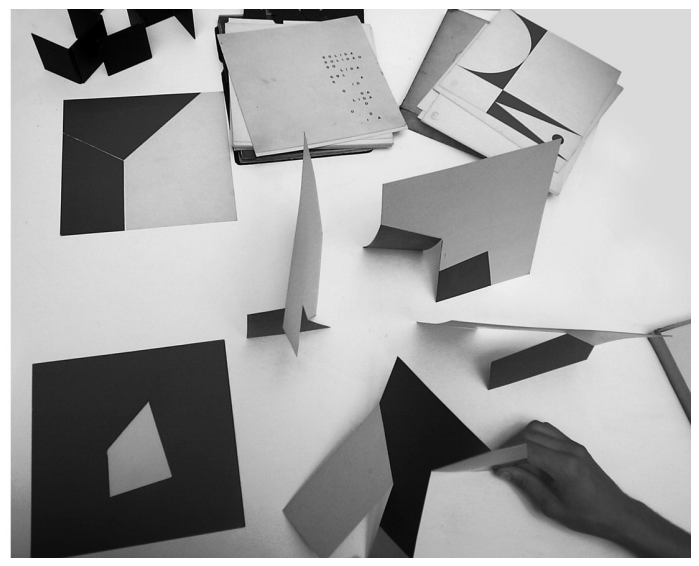

Solida (WDP) acervo Neide de Sá 